\title{
Genetics of congenital nemaline myopathy: a study of 10 families
}

Carina Wallgren-Pettersson, Helena Kääriäinen, Juhani Rapola, Tapani Salmi, Jaakko Jääskeläinen, Märta Donner

\begin{abstract}
In order to investigate the inheritance in congenital nemaline myopathy (CNM), we studied the family histories and pedigrees of 13 patients with CNM from 10 families, and the 20 parents, by physical examination, single fibre electromyography, ultrasonography of muscles, measurement of serum creatine kinase, muscle biopsy, and electrophoresis of muscle proteins. None of the parents was affected. In three families there were two affected children. Of the parents, 15 showed deficiency of type 2B muscle fibres, and all except one father showed some other minor neuromuscular abnormality. These may represent heterozygous manifestations of a recessive gene. Most of the ancestors came from sparsely populated rural communities in the west of Finland.

We conclude that in the Finnish CNM patients, the mode of inheritance appears to be recessive. Apart from a few instances of dominant inheritance, most cases published also seem compatible with recessive inheritance.
\end{abstract}

Congenital nemaline myopathy (CNM) was first described in $1963 .{ }^{12}$ It is characterised by generalised

The Children's Hospital, University of Helsinki, Stenbäckink 11, SF-00290 Helsinki, Finland.

C Wallgren-Pettersson, J Jääskeläinen, M Donner

Department of Medical Genetics, Väestöliitto, Helsinki, Finland.

H Kääriäinen

Department of Pathology, University of Helsinki, Finland. J Rapola

Department of Neurology, University of Helsinki, Finland.

T Salmi

Correspondence to Dr Wallgren-Pettersson.

Received for publication 25 October 1989

Revised version accepted for publication 13 February 1990. muscular weakness and hypotonia from birth or infancy. Further characteristics are myopathic facies, high arched palate, and often chest deformities and scoliosis. The diagnosis is confirmed by a skeletal muscle biopsy stained by the Gomori trichrome method, which shows the presence of abundant, thread-like (Greek nema=thread) particles, the nemaline bodies, in the myofibres, and often predominance of type 1 muscle fibres.

The clinical picture of CNM is uniform, but the severity varies widely. A subclassification of nemaline myopathy into an early fatal form, a more benign congenital form, ${ }^{3}$ and an adult onset form ${ }^{4}$ has been suggested. No clear histological differences have been found between these subgroups. ${ }^{5}$ However, the adult onset form differs from the other two in several ways. Besides having a later age of onset, it is usually preceded by an inflammatory disease, and characterised by a progressive course and absence of dysmorphic features. Thus, the adult onset form probably represents a different disease entity.

CNM is generally thought to be a hereditary disease, but the mode of inheritance is not clear. In some families the trait shows an autosomal dominant pattern (McKusick *16180), ${ }^{6-9}$ and in others seems to be recessive (McKusick $\left.{ }^{*} 25603\right) .{ }^{6}$ In a survey of 50 published cases, ${ }^{10}$ autosomal dominant inheritance with reduced penetrance was suggested.

In this study we examined the family history and pedigree data of 10 families with $13 \mathrm{CNM}$ patients. In addition, we report the results of clinical examination of the 20 parents, including single fibre electromyography, ultrasonography of muscles, serum creatine kinase, muscle biopsy, and electrophoresis of muscle proteins.

Subjects and methods

PATIENTS

We examined all 13 CNM patients known in Finland at the time of this study. Their diagnoses were based on clinical features consistent with congenital myopathy $^{11}$ and the presence of nemaline bodies in a muscle biopsy. Twelve of the patients had been 
ascertained among the 400 patients under 16 years of age with neuromuscular disease diagnosed at the University of Helsinki Children's Hospital in 1964 to 1985. ${ }^{12}$ The thirteenth patient was a mildly affected sister of a proband; she was diagnosed at the time of the follow up study. Nine of the patients were female and four were male (aged 5 to 40 years, mean 18 years). The results of the patients have been published previously ${ }^{12-15}$ and a summary is provided in table 1 .

\section{PARENTS}

All the parents ( 10 mothers and 10 fathers aged 31 to 64 years, mean 45 years) of the patients with CNM were studied by physical examination, single fibre electromyography, ultrasonography of the lower limb muscles, serum creatine kinase determination, muscle biopsy, and electrophoresis of muscle proteins.

\section{FAMILY HISTORIES}

Family histories were taken and, if positive for any neuromuscular symptoms or chronic diseases, checked from hospital records. From the family histories and the population register, the grandparents and great grandparents were sought for determination of the geographical distribution of their birthplaces and any close consanguinity between ancestors.

\section{SINGLE FIBRE ELECTROMYOGRAPHY}

Measurements of fibre density were performed by a computerised method in the extensor digitorum communis muscle with a concentric needle electrode. $^{1316}$

\section{ULTRASONOGRAPHY}

Ultrasonography was done with a real time apparatus with a $7 \cdot 5 \mathrm{MHz}$ sector scanner. Longitudinal and

Table 1 Characteristic findings in patients with congenital nemaline myopathy. ${ }^{12}$

Muscle weakness most pronounced in face, neck, trunk, and distal parts of limbs (13/13).

Inability to run (13/13).

Hypermobility of joints (7/12).

Absence of tendon (12/12) and palatal (9/12) reflexes.

Diadochokinesis slow or clumsy $(6 / 12)$.

Abnormally high fibre density at single fibre electromyography $(9 / 10)$.

Abnormally high (grade 2-4) echogenicity on ultrasonography of thigh $(10 / 12)$ and shin $(12 / 12)$ muscles.

Nemaline bodies in muscle biopsy (13/13).

Predominance $(>55 \%)$ of type 1 (slow) fibres in muscle biopsy (12/13).

Absence of type 2B (fast fatiguable) fibres in muscle biopsy (10/12). Abnormally shaped histograms of muscle fibre diameter (10/13).

Abnormally high variability coefficients of muscle fibre diameter (12/13).

Internal nuclei (7/12), splitting of fibres (2/13), or endomysial fat or fibrosis $(9 / 12)$ in muscle biopsy.

Deficiency of $\alpha$-actinin $(9 / 13)$ and a 65 kd (6/13) protein on electrophoresis of muscle proteins. transverse scans at mid-thigh and mid-calf were taken from the quadriceps femoris muscles, the plantar flexors of the feet, and the dorsiflexors of the feet. The findings were graded from 1 to 4 , using a modification of the scale of Heckmatt and Dubowitz, ${ }^{17}$ grade 1 representing normal scans and grades 2 to 4 pathological scans of increasing abnormality. ${ }^{14}$

\section{SERUM CREATINE KINASE}

Serum creatine kinase was determined by a routine spectrophotometric method, the upper limit of normal in our laboratory being $150 \mathrm{IU} / \mathrm{l}$.

\section{MUSCLE BIOPSY}

Biopsies were obtained from the quadriceps femoris muscle under local anaesthesia with a Bergström or Tru-Cut ${ }^{R}$ needle at a site one third of the distance from the joint space of the knee to the trochanter major. The samples were immediately orientated under a dissecting microscope and frozen in freon cooled with liquid nitrogen. Cryostat sections $(10 \mu \mathrm{m})$ were stained with the haematoxylin-eosin (HE), Gomori trichrome, and myosin adenosine triphosphatase (ATPase) methods, the latter after preincubation at $\mathrm{pH} 4 \cdot 3,4 \cdot 6$, and $9 \cdot 4$. Trichrome and HE stained sections were examined for nemaline bodies and secondary signs of myopathy, respectively.

Two hundred fibres in each sample were classified as type 1, 2A, 2B, or $2 \mathrm{C}$ and measured from photomicrographs of ATPase stained sections. Histograms of fibre diameters were plotted separately for each fibre type. ${ }^{15}$ The mean fibre diameters, standard deviations, variability coefficients, and atrophy and hypertrophy factors were calculated. ${ }^{18} 19$

\section{ELECTROPHORESIS OF MUSCLE PROTEINS}

Muscle proteins were extracted from the biopsies according to Stuhlfauth et al. ${ }^{20}$ One dimensional sodium dodecyl sulphate polyacrylamide gradient gel electrophoresis was performed, using a modification of the methods of Laemmli ${ }^{21}$ and O'Farrell. ${ }^{22}$

\section{CONTROL STUDIES}

Ultrasonography of the lower limbs was done in 14 healthy control subjects from the medical staff (aged 18 to 65 years, mean 37 years). Results of single fibre electromyography in 64 healthy controls ( 38 females and 26 males aged 20 to 84 years, mean age 46 years) have been published previously. ${ }^{16}$ With the method used, the mean fibre density for the extensor digitorum communis muscle is $1 \cdot 17$, the upper limit of normal being $1 \cdot 27$ (mean +2 SD). Five muscle biopsies from controls (aged 13 to 32 years, mean 21 years) were processed in the same way as the parents' biopsies. Control biopsies 1 to 3 were obtained during orthopaedic surgery for unrelated causes, and control 
biopsies 4 and 5 were from healthy_volunteers from the medical staff. Three of the biopsies were from the quadriceps femoris muscle, no 2 was from the gracilis, and no 3 from the hamstring muscles. Parts of the control biopsies were used for electrophoresis in the same way as those from the patients and parents.

\section{Results}

\section{FAMILY HISTORIES}

The 13 patients came from 10 families (fig 1). In three families there were two affected sibs, in whom the disease differed somewhat in severity, and the other seven patients were the only affected persons in the family. None of the parents reported any symptoms of muscular disease. Grandparents, aunts and uncles, and the children of these were also reportedly unaffected. One mildly affected patient had two healthy children (family 8 , fig 1 ), and a severely affected patient (family 9, fig 1) gave birth to a clinically healthy son in June 1989. Physical examination of the boy at birth and at 2 months of age showed no signs of CNM.

No consanguineous marriages were found and the families were not found to be related. However, several of the grandparents originated from sparsely populated rural communities in the west of Finland (fig 2).

There were four male and nine female patients; thus the sex ratio was $0 \cdot 44$. The 13 patients had 12

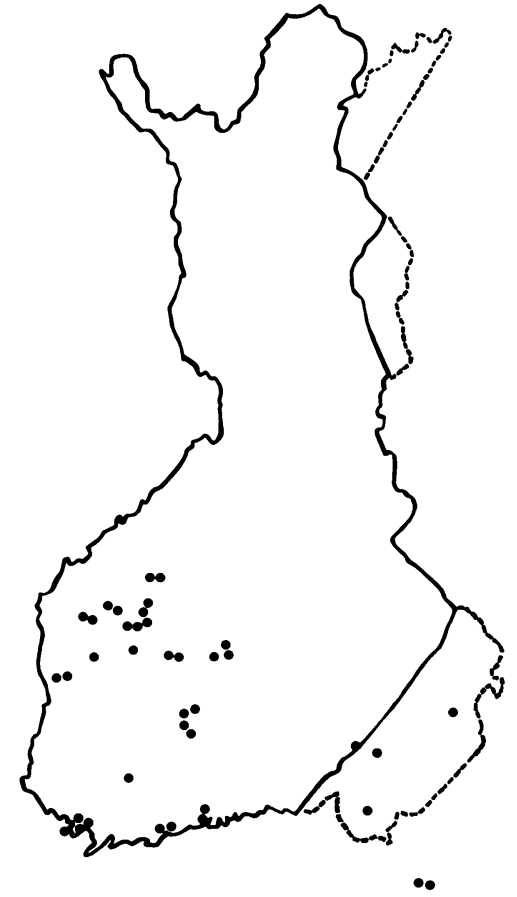

Figure 2 The birthplaces of the grandparents of the patients with CNM, showing clustering in sparsely populated rural communities in the western part of Finland. Each dot marks the birthplace of one grandparent. The areas enclosed by the broken line were parts of Finland before the second world war.
Family 1

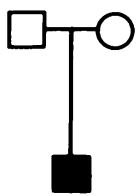

Family 2

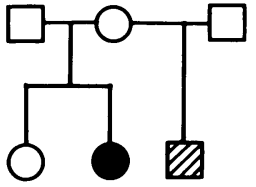

Family 6

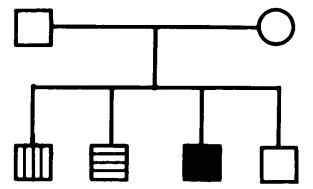

Family 7
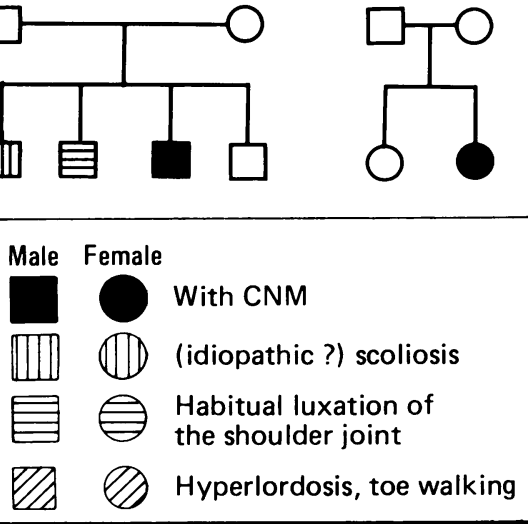

Family 3
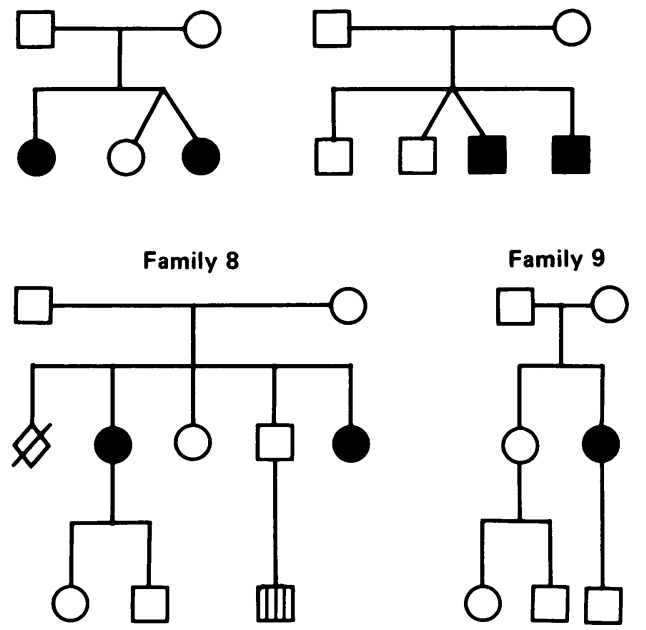

Family 4

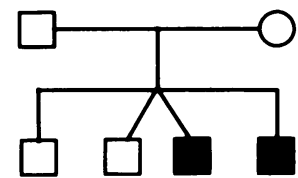

Family 10
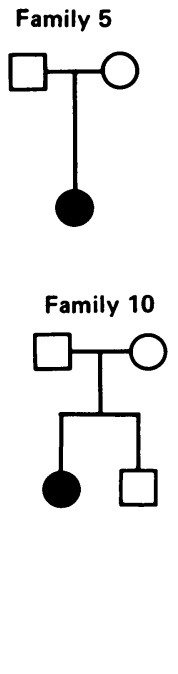

Figure 1 Pedigrees of the 10 families of patients with CNM. 
unaffected sibs. In addition, in family 8 there was one stillborn sib whose cause of death was not known. A brother (family 6) and a nephew (family 8) had scoliosis. Another brother (family 6) had habitual luxation of the shoulder joint. Both the brothers and the nephew allegedly had normal muscle power. A half brother (family 2) had hyperlordosis of the spine and was a toe walker, but on examination at the age of 17 his muscle strength was normal. Two of the unaffected sibs were twins of patients. DNA fingerprint analysis confirmed that the twins were nonidentical.

The proportion of affected sibs was 0.268 when corrected for truncate complete ascertainment by Apert's a priori method, and $\mathbf{0 . 2 0}$ when corrected for truncate single ascertainment by omitting one affected sib from each sibship. ${ }^{23}$ The stillborn sib was omitted from these calculations.

\section{CLINICAL FINDINGS IN THE PARENTS}

None of the parents had CNM, but judged by a careful physical examination seven mothers and seven fathers showed minor neuromuscular abnormalities (table 2) of which, as a rule, they were not aware.

\section{SINGLE FIBRE ELECTROMYOGRAPHY}

On single fibre electromyography of the extensor digitorum communis muscle, two fathers showed fibre densities higher than normal $(1.35$ and 1.40 , respectively) (table 2 ). In all the other parents, fibre density was normal. The probands had a mean fibre density of 1.54 (range $1 \cdot 29$ to $2 \cdot 07$ )..$^{13}$

\section{ULTRASONOGRAPHY}

In the thigh muscles all parents showed normal echogenicity, and in the calves or shins five mothers and two fathers showed slightly greater (grade 2) echogenicity than normal. Ultrasonography of the controls showed completely normal scans in 10 and a slightly greater echogenicity than normal (grade 2 ) in the thighs or calves in four.

Table 2 Minor neuromuscular abnormalities in healthy parents of patients with congenital nemaline myopathy.

\begin{tabular}{|c|c|c|c|c|c|c|c|c|c|}
\hline $\begin{array}{l}\text { Mother } \\
\text { No }\end{array}$ & $\begin{array}{l}\text { Clinical } \\
\text { finding }\end{array}$ & $\begin{array}{l}\text { Hist } \\
2 \mathrm{~B}-/ \\
\text { other }\end{array}$ & $\begin{array}{l}\text { El } \\
\text { ph }\end{array}$ & EMG & $\begin{array}{l}\text { Father } \\
\text { No }\end{array}$ & $\begin{array}{l}\text { Clinical } \\
\text { finding }\end{array}$ & $\begin{array}{c}\text { Hist } \\
\text { 2B- } / \\
\text { other }\end{array}$ & $\begin{array}{l}\text { El } \\
\text { ph }\end{array}$ & EMG \\
\hline 1 & $\begin{array}{l}\text { Deviant facial appearance* } \\
\text { Facial weakness } \\
\text { High arched palate } \\
\text { Habitual subluxation } \\
\text { of patella }\end{array}$ & $+1+$ & + & - & 1 & - & $-1-$ & - & - \\
\hline 2 & $\begin{array}{l}\text { Subluxation of hip } \\
\text { Pain in elbows } \\
\text { after carrying } \\
\text { heavy loads }\end{array}$ & $+1+$ & + & - & 2 & - & $+1+$ & + & - \\
\hline 3 & $\begin{array}{l}\text { DDK clumsier on } \\
\text { dominant side }\end{array}$ & $+1+$ & - & - & 3 & $\begin{array}{l}\text { Weak tendon } \\
\text { reflexes }\end{array}$ & $+1-$ & - & + \\
\hline 4 & $\begin{array}{l}\text { Dorsiflexors of } \\
\text { right foot thin }\end{array}$ & $+1+$ & - & - & 4 & Facial weakness & $-1+$ & - & - \\
\hline 5 & - & $+1+$ & + & - & 5 & $\overline{\mathrm{D}} \overline{\mathrm{D}} \overline{\mathrm{K}}$ slow, clumsył & $-1+$ & - & - \\
\hline 6 & - & $+1+$ & - & & 6 & $\begin{array}{l}\text { Weak palatal } \\
\text { reflex }\end{array}$ & $+1+$ & + & \\
\hline 7 & $\begin{array}{l}\text { Facial weakness } \\
\text { Dorsiflexors of left } \\
\text { foot thin }\end{array}$ & $+1+$ & - & - & 7 & Inability to run fast & $+1-$ & - & - \\
\hline 8 & $\begin{array}{l}\text { Facial weakness } \\
\text { Biceps reflexes weak }\end{array}$ & $-1+$ & + & - & 8 & - & $+1+$ & - & - \\
\hline 9 & - & $+1+$ & - & - & 9 & $\begin{array}{l}\text { Slight facial and } \\
\text { finger weakness }\end{array}$ & $-1+$ & - & + \\
\hline 10 & DDK slow & $+1+$ & - & - & 10 & $\begin{array}{l}\text { Weak fingers } \\
\text { Clumsiness (DDK } \\
\text { and fine motor) } \\
\text { Right calf } 1 \mathrm{~cm} \\
\text { thinner }\end{array}$ & $+1+$ & + & - \\
\hline
\end{tabular}

Hist 2B-/ other + =muscle biopsy shows deficiency of type 2B fibres/or some other abnormality, ie above normal numbers of internal nuclei, splitting of fibres, abnormally shaped histograms of fibre diameter, abnormally great variability of fibre diameter and/or abnormal atrophy factors. El ph=electrophoresis of muscle proteins, $+=$ deficiency of $\alpha$-actinin and/or a $65 \mathrm{kd}$ protein. EMG=single fibre electromyography, $+=$ abnormally high fibre density. ${ }^{*}=$ Elongated face with small muscle bulk, micrognathia, and expressionless appearance at rest, but with normal facial expressions during conversation. $\dagger=$ Facial weakness slight in all cases, mostly inability to keep air in cheeks against pressure. $\ddagger=$ Possibly owing to toxic agent. DDK=diadochokinesis. Blank=examination not done. 


\section{CREATINE KINASE}

Serum creatine kinase concentrations were slightly higher than normal in two mothers (243 IU/l in mother 6 and $183 \mathrm{IU} / 1$ in mother 8 ).

\section{MUSCLE HISTOLOGY}

No nemaline bodies were found in the parents' muscle biopsies. Five mothers and four fathers showed some of the following abnormalities: fibre type grouping (3/20), small angulated fibres $(3 / 20)$, above normal numbers of internal nuclei $(5 / 20)$, or splitting of fibres $(4 / 20)$. None of the parents had endomysial or perimysial fat or fibrosis and none had necrotic or regenerating fibres.
Four of the 10 mothers and five of the 10 fathers had predominance $\left(>55 \%{ }^{19}\right)$ of type 1 fibres (table 3 , figs 3 and 4$)$. Eight mothers and five fathers showed deficiency $\left(<10 \%{ }^{19}\right)$ of type $2 \mathrm{~B}$ fibres, and one further mother and one father showed total lack of type 2B fibres. One mother and four fathers had a normal fibre type composition.

Three controls (no 3, 4, and 5) showed slight predominance of type 1 fibres (table 3 ). One control (no 4 , one of the healthy volunteers) had deficiency of type $2 \mathrm{~B}$ fibres.

As in the probands, ${ }^{15}$ the histograms of muscle fibre diameter in the parents showed abnormal distributions of three types (fig 3): a flattened and bilaterally broadened curve, skewing towards the

Table 3 Fibre type composition in parents of C:NM patients and in controls.

\begin{tabular}{|c|c|c|c|c|c|c|c|c|c|c|c|}
\hline \multirow{2}{*}{$\begin{array}{l}\text { Mother } \\
\text { No }\end{array}$} & \multirow[b]{2}{*}{ Age } & \multicolumn{4}{|c|}{ Fibre tvpe $(\%)$} & \multirow{2}{*}{$\begin{array}{l}\text { Father } \\
\text { No }\end{array}$} & \multirow[b]{2}{*}{ Age } & \multicolumn{4}{|c|}{ Fibre type ( $1 / 10)$} \\
\hline & & 1 & $2 \mathrm{~A}$ & $2 \mathrm{~B}$ & $2 \mathrm{C}$ & & & 1 & $2 \mathrm{~A}$ & $2 \mathrm{~B}$ & $2 \mathrm{C}$ \\
\hline 1 & 31 & 54 & $39 \cdot 5$ & $5 \cdot 5$ & 1 & 1 & 33 & 32 & 25 & 43 & \\
\hline 2 & 38 & $41 \cdot 5$ & 55 & 3 & 0.5 & 2 & 37 & 72 & $24 \cdot 5$ & $3 \cdot 5$ & \\
\hline 3 & 41 & $74 \cdot 5$ & $25 \cdot 5$ & - & & 3 & 40 & 73 & $25 \cdot 5$ & 1.5 & \\
\hline 4 & 42 & $53 \cdot 5$ & 46 & 0.5 & & 4 & 43 & 54 & 26 & $19 \cdot 5$ & 0.5 \\
\hline 5 & 41 & $74 \cdot 5$ & 21 & 3 & $1 \cdot 5$ & 5 & 45 & $34 \cdot 5$ & 53 & $12 \cdot 5$ & \\
\hline 6 & 48 & $34 \cdot 5$ & 64 & $1 \cdot 5$ & & 6 & 52 & $39 \cdot 5$ & 59 & 1.5 & \\
\hline 7 & 47 & $38 \cdot 5$ & 52 & 9.5 & & 7 & 45 & 63.5 & $36 \cdot 5$ & - & \\
\hline 8 & 64 & $46 \cdot 5$ & 22 & $29 \cdot 5$ & 2 & 8 & 60 & $81 \cdot 5$ & $15 \cdot 5$ & $2 \cdot 5$ & 0.5 \\
\hline 9 & 50 & $64 \cdot 5$ & 33 & 1 & $1 \cdot 5$ & 9 & 52 & $50 \cdot 5$ & $15 \cdot 5$ & $33 \cdot 5$ & 0.5 \\
\hline 10 & 48 & 72 & 215 & $6 \cdot 5$ & & 10 & 47 & $76 \cdot 5$ & 13 & $9 \cdot 5$ & 1 \\
\hline $\begin{array}{l}\text { Female } \\
\text { control }\end{array}$ & & & & & & $\begin{array}{l}\text { Male } \\
\text { control }\end{array}$ & & & & & \\
\hline 1 & 13 & 47 & $37 \cdot 5$ & $15 \cdot 5$ & & 2 & 13 & $41 \cdot 5$ & 13.5 & 43.5 & $1 \cdot 5$ \\
\hline 3 & 13 & 61 & 23 & 16 & & & & & & & \\
\hline 4 & 31 & $68 \cdot 5$ & $27 \cdot 5$ & 4 & & 5 & 32 & 57 & 27 & 16 & \\
\hline
\end{tabular}
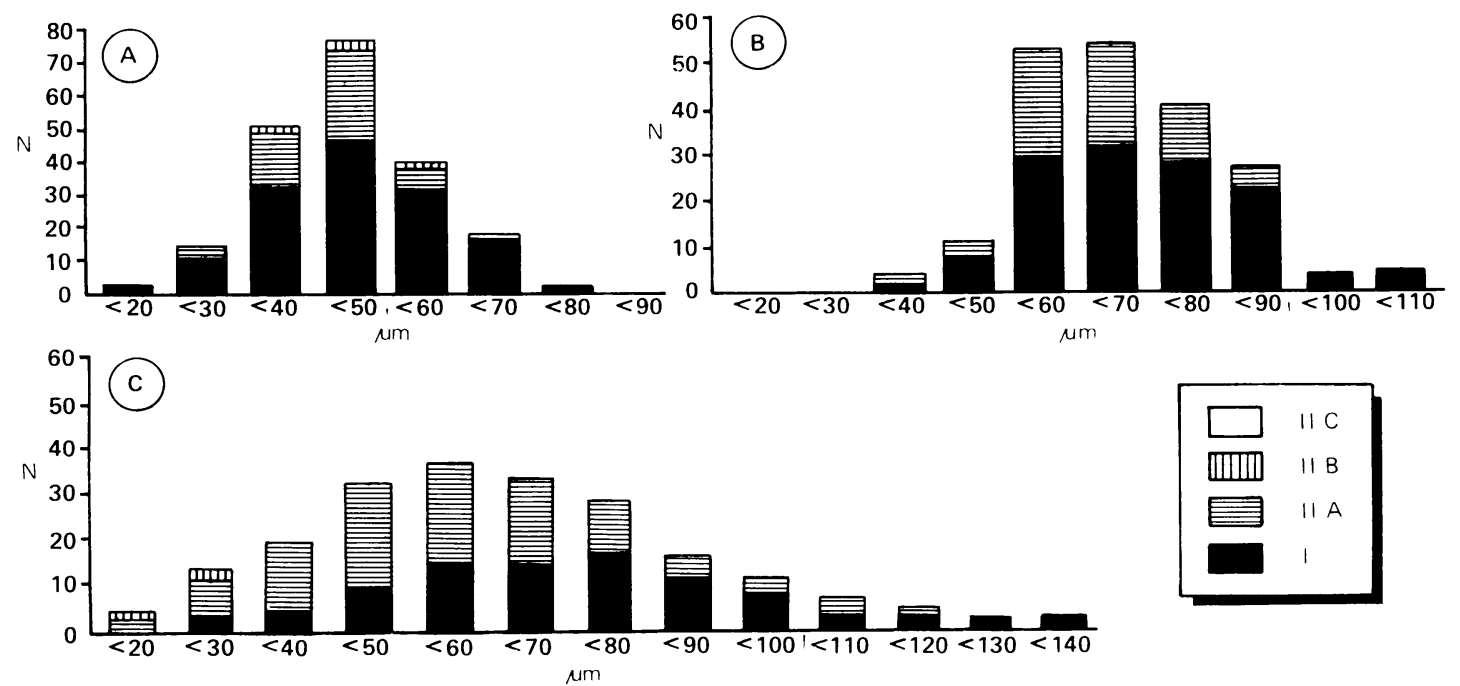

Figure 3 Histograms of muscle fibre diameters in one healthy female control $(A)$ and in two fathers $(B, C)$ of patients with $C N M$. The histogram of the control has the normal bell shaped appearance $(A)$. Note in father $7(B)$ the total lack of type $2 B$ fibres, and in father $6(C)$ the broad and flat shape of the histogram as well as the smallness and deficiency of type $2 B$ fibres. 


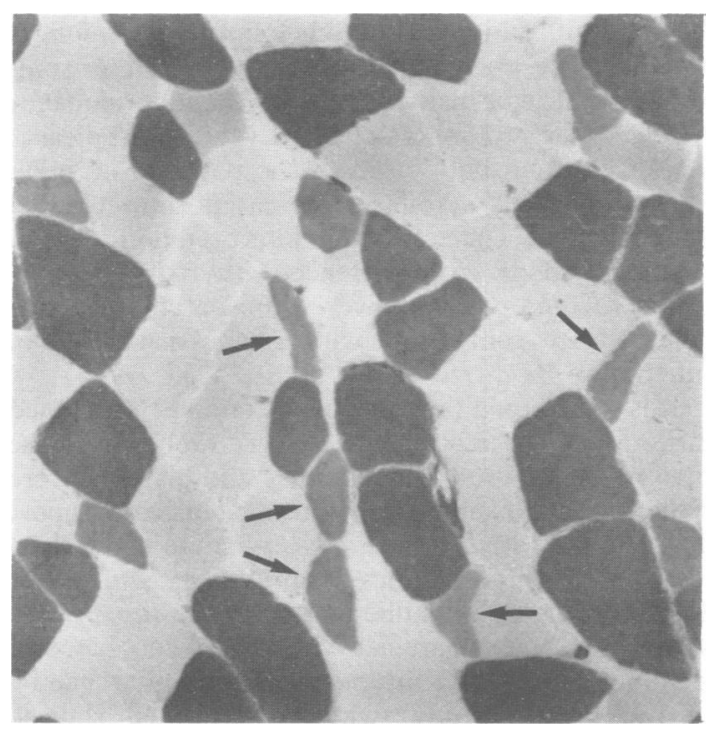

Figure 4 Section of muscle biopsy from mother 7 stained by the ATPase method after preincubation at $\mathrm{pH} 4 \cdot 6$, showing a few small, grey type $2 B$ fibres (arrows) scattered among larger type 1 (black) and type $2 A$ (white) fibres. The fibre types were determined from adjacent sections stained with ATPase after preincubation at $p H 9 \cdot 4$ and $4 \cdot 3$, respectively.

atrophic end, or bimodal or trimodal histograms. Parent and proband did not always show the same abnormality. Two mothers and five fathers had the normal bell shaped histogram characteristic of the controls. In two of the parents the mean fibre diameters deviated clearly from those of the controls, the type $2 \mathrm{~B}$ fibres being smaller than normal in these parents, both of whom had type $2 \mathrm{~B}$ deficiency. The mean fibre diameters of our controls compared well with published normal values. ${ }^{18} 24-27$

The variability coefficients $(\mathrm{VC}=\mathrm{SD} /$ mean fibre diameter $\times 1000$ ) were greater than normal $(250)^{19}$ for the type 1 fibres in five mothers and four fathers, for the type $2 \mathrm{~A}$ fibres in five mothers and three fathers, and for the type 2B fibres in six of the seven mothers and five of the nine fathers for whom they could be calculated. Thus, all the mothers and six of the fathers had an abnormally high variability coefficient for at least one fibre type. The controls had normal or nearly normal variability coefficients.

\section{ELECTROPHORESIS OF MUSCLE PROTEINS}

Three mothers and one father showed deficiency or total lack of $\alpha$-actinin, and two mothers and two fathers showed total lack of a $65 \mathrm{kd}$ protein. Both these proteins were present in all controls but deficient in nine and six of the probands, respectively.

Summarising the investigations in the parents, none of them had CNM, but in all parents except father 1 some of the neuromuscular abnormalities characteristic of the probands were found (table 2). In family 1 paternity was confirmed with DNA fingerprint analysis.

\section{Discussion}

It is generally accepted that CNM is a hereditary disorder, and an exogenic cause for the characteristic congenital symptoms and signs is seldom even discussed. In our series there were two pairs of nonidentical twins discordant for CNM. Thorough histories of pregnancy failed to disclose any possible risk factor common to the 10 mothers. Thus our results are in keeping with the view that an exogenic cause for CNM is unlikely.

CNM is a rare disease and articles on CNM mostly consist of case reports. This series of extensively examined parents of patients with CNM is to our knowledge the largest one published hitherto, and therefore enables us to shed some new light on the mode of inheritance in CNM. However, it was not possible to examine the healthy sibs of the patients. Another difficulty was the lack of a large normal series of human muscle biopsies, hampering interpretation of the many different slightly pathological features in the muscle biopsies of the parents. The series published ${ }^{24-27}$ have all been relatively small and ours consisted of only five biopsies. A reference series widely in use comprises biopsies obtained on suspicion of neuromuscular disease but found to be normal. ${ }^{18}$

Among the methods tried in this study to search for minor neuromuscular abnormalities in the parents, ultrasonography does not seem to be a useful one. The small excess of serum creatine kinase in two mothers could be from causes unrelated to CNM, especially since the patients showed normal levels. Fibre type grouping or small angulated fibres were not included among the pathological muscle biopsy features in table 2 , since these were not found in the probands, and fibre type grouping is a normal feature of ageing muscle.

Increased fibre density in single fibre electromyography indicates altered distribution of the muscle fibres of a motor unit. It is known to be a sensitive quantitative detector of neuromuscular abnormality. ${ }^{1628}$ Specificity is not very good, however, and high fibre densities are found in both neurogenic and myopathic disorders and as late sequelae of various disorders. In this study only two fathers showed fibre densities higher than normal. The significance of the electrophoretic findings remains to be clarified.

One abnormality was present in $75 \%$ of the biopsies of the parents, that is, deficiency or total lack of type 2B fibres, mostly combined, as in the probands, with predominance of type 1 fibres (table 3 , figs 3 and 4). 
One of our healthy controls from the medical staff exhibited a similar deficiency. We do not know the reason for this. The control differed, as far as we are aware, from all previously published controls ${ }^{24-27}$ of compatible age. In a study of 34 healthy male subjects biopsied twice, the proportion of type 1 fibres varied by as much as $6 \cdot 2$ to $12.3 \%{ }^{29}$ This variation is naturally to be expected in the parents as well, but hardly accounts for the presence of the deficiency in as many as 15 of the parents. Predominance of type 1 fibres has previously been noted in three mothers of CNM patients, ${ }^{7031}$ but most reports of parental biopsies fail to describe fibre type distribution.

The two main findings in this study were that in none of the families were two generations affected, and that in all but one of the families physical examination, electromyography, histological examination of muscle biopsies, or electrophoresis of muscle proteins (table 2) showed minor neuromuscular abnormalities in both parents. Thus, these minor abnormalities probably represent heterozygous manifestations of an autosomal recessive gene. This interpretation is corroborated by the fact that all the parents had normal muscle power. The only exceptions are those listed in table 2 , and the parents themselves were unaware of them. The proportion of affected sibs was 0.268 and 0.20 , respectively, when corrected for truncate complete and single ascertainment. These figures are in accord with recessive inheritance, ${ }^{32}$ and suggest that the ascertainment was between complete and single. The small number of families, however, reduces the value of segregation analysis. The sex ratio is also compatible with a recessive mode of inheritance. Most of the families originated from sparsely populated rural areas in the western parts of Finland (fig 2) that were permanently settled in the 16th century by relatively few founders. This is a common finding in corresponding maps of rare recessive disorders in Finland: most of the ancestors come from sparsely populated areas consisting of local isolates. ${ }^{33}$ Thus, this map (fig 2) can be considered to support a recessive mode of inheritance.

Family histories published in 50 cases of CNM have been analysed by Kondo and Yuasa. ${ }^{10}$ Among the 44 families reported, three showed a dominant mode of inheritance with clinically overt CNM verified by biopsy in two generations. ${ }^{7-9}$ However, one of these ${ }^{7}$ could have been pseudodominant, as the parents of the affected person in the second generation were remotely related. Altogether, parental consanguinity was reported in five families. Arts and de Groot ${ }^{34}$ calculated that when families with CNM in two or more generations were excluded the proportion of consanguineous marriages was $5 / 43$, a high proportion which suggests recessive inheritance. In the study by Kondo and Yuasa, ${ }^{10}$ there were 37 families in which both parents were healthy, and in eight of these there were two or more affected children. In 12 families both parents underwent muscle biopsy, and in four of these families one of the parents showed either some of the physical or histological abnormalities (nemaline bodies or large numbers of internal nuclei) typical of CNM, in four both parents showed one or other abnormality, and in four neither parent showed either abnormality. The authors' interpretation was a dominant mode of inheritance with reduced penetrance. In our opinion, however, most of the pedigrees analysed are compatible with a recessive mode of inheritance.

It is to be noted that four of the families ${ }^{35}$ included in the report by Kondo and Yuasa ${ }^{10}$ took part in the present study, and the patients and parents were rebiopsied and examined with more extensive methods. The parents who at the first examination showed no histological abnormalities (families 1 and 3 of Kuitunen et al, ${ }^{35}$ families 6 and 7 in the present study), and the parents who were not biopsied (families 2 and 4 of Kuitunen $e t$ al,,$^{35}$ families 5 and 9 in the present study) when re-examined showed minor physical or histological abnormalities typical of CNM. Thus it is possible that more extensive methods of investigation, if applied to other apparently healthy parents, might show manifestations of heterozygosity in these too.

We conclude that in most cases of CNM, including the Finnish patients, the most likely mode of inherio tance is recessive. However, it should be borne in mind that there have been a few instances of dominane inheritance.

This work was supported by grants from Finska Läkaresällskapet, the Foundation for Paediatric Research, Finland, and the Sigrid Jusélius Foundation, Finland. The authors thank Ms Marjut Appelqvist, Ms Pirkko Niemelä, Mr Esa Kohtamäki, and Ms Sinikka Tsupari for expert technical assistance. This study has been approved by the Ethical Committee of the Children's Hospital, University of Helsinki.

1 Shy GM, Engel WK, Somers JE, Wanko T. Nemaline myopathy. A new congenital myopathy. Brain 1963;79:793-810.

2 Conen PE, Murphy EG, Donohue WL. Light and electron microscopic studies of "myogranules" in a child with hypotonia and muscle weakness. Can Med Assoc F 1963;89:983-6.

3 Martinez BA, Lake BD. Childhood nemaline myopathy: a review of clinical presentation in relation to prognosis. Dev Med ('hild Neurol 1987;29:815-20.

4 Engel WK, Resnick JS. Late-onset rod myopathy: a newly recognized, acquired, and progressive disease. Neurology 1966; 16:308-9.

5 Shimomura C, Nonaka I. Nemaline myopathy: comparative muscle histochemistry in the severe neonatal, moderate congenital, and adult-onset forms. Pediatr Neurol 1989;5:25-31.

6 McKusick VA. Mendelian inheritance in mun. Catalogs of autosomal dominant, autosomal recessive, and $X$-linked phenotypes. 8th ed. Baltimore, London: Johns Hopkins University Press, 1988:517, 1097.

7 Arts WF, Bethlem J, Dingemans KP, Eriksson AW. Investigations on the inheritance of nemaline myopathy. Arch Neurol 1978;35:72-7.

8 Spiro AJ, Kennedy C. Hereditary occurrence of nemaline myopathy. Arch Neurol 1965;13:155-9. 
9 Hopkins IJ, Lindsey JR, Ford FR. Nemaline myopathy. A longterm clinicopathologic study of affected mother and daughter. Brain 1966;89:299-311.

10 Kondo K, Yuasa T. Genetics of congenital nemaline myopathy. Muscle Nerve 1980;3:308-15.

11 Dubowitz V. Muscle disorders in childhood. Philadelphia: Saunders, 1978:77-83.

12 Wallgren-Pettersson C. Congenital nemaline myopathy. A clinical follow-up study of twelve patients. F Neurol Sci 1989;89:1-14.

13 Wallgren-Pettersson C, Sainio K, Salmi T. Electromyography in congenital nemaline myopathy. Muscle Nerve 1989;12:587-93.

14 Wallgren-Pettersson C, Kivisaari L, Jääskeläinen J, Lamminen A, Holmberg C. Ultrasonography, CT and MRI of muscles in congenital nemaline myopathy. Pediatr Neurol 1990;6:20-8.

15 Wallgren-Pettersson C, Rapola J, Donner M. Pathology of congenital nemaline myopathy. A follow-up study. 7 Neurol Sci 1988;83:243-57.

16 Salmi T. Automatic analysis of single fibre composition of motor unit potentials in clinical electromyography. Dissertation, University of Helsinki, 1985:106.

17 Heckmatt JZ, Dubowitz V. Diagnosis of spinal muscular atrophy with pulse echo ultrasound imaging. In: Gamstorp I, Sarnat HB, eds. Progressive spinal muscular atrophies. New York: Raven Press, 1984:141-51.

18 Brooke $M H$, Engel WK. The histographic analysis of human muscle biopsies with regard to fiber types. 1. Adult male and female. Neurology 1969;19:221-33.

19 Dubowitz V. Muscle biopsy: a practical approach. 2nd ed. London: Balliere Tindall, 1985:82-128.

20 Stuhlfauth I, Jennekens FG, Willemse J, Jockusch BM. Congenital nemaline myopathy. II. Quantitative changes in $\alpha$ actinin and myosin in skeletal muscle. Muscle Nerve 1983;6 69-74.

21 Laemmli UK. Cleavage of structural proteins during the assembly of the head of bacteriophage T4. Nature 1970;227:680-5.

22 O'Farrell PH. High resolution two-dimensional electrophoresis of proteins. F Biol Chem 1975;250:4007-21.

$23 \mathrm{Li} \mathrm{CC.} \mathrm{Human} \mathrm{genetics.} \mathrm{Principles} \mathrm{and} \mathrm{methods.} \mathrm{New} \mathrm{York:}$ McGraw-Hill, 1961.
24 Johnson MA, Sideri G, Weightman D, Appleton D. A comparison of fibre size, fibre type constitution and spatial fibre type distribution in normal human muscle and in muscle from cases of spinal muscular atrophy and from other neuromuscular disorders. I Neurol Sci 1973;20:345-61.

25 Maunder-Sewry C, Dubowitz V. Needle muscle biopsy for carrier detection in Duchenne muscular dystrophy. Part 1. Light microscopy, histology, histochemistry and quantitation. f Neurol Sci 1981;49:305-24.

26 Doriguzzi C, Mongini T, Palmucci L, Gagnor E, Schiffer D. Quantitative analysis of quadriceps muscle biopsy. Results in 30 healthy females. I Neurol Sci 1984;66:319-26.

27 Mahon M, Toman A, Willan PLT, Bagnall KM. Variability of histochemical and morphometric data from needle biopsy specimens of human quadriceps femoris muscle. $\mathcal{J}$ Neurol Sci 1984;63:85-100.

28 Stålberg E, Trontelj J. Single fibre electromyography. Old Woking: Mirvalle Press, 1979:1-244.

29 Blomstrand E, Ekblom B. The needle biopsy technique for fibre type determination in human skeletal muscle-a methodological study. Acta Physiol Scand 1982;116:437-42.

30 Bender AN, Willner JP. Nemaline (rod) myopathy: the need for histochemical evaluation of affected families. Ann Neurol 1978;4:37-42.

31 Volpe P, Damiani E, Margreth A, Pellegrini G, Scarlato G. Fast to slow change of myosin in nemaline myopathy: electrophoretic and immunologic evidence. Neurology 1982;32:37-41.

32 Emery AEH. Methodology in medical genetics. An introduction to statistical methods. Edinburgh: Churchill Livingstone, 1976: $35-50$.

33 Norio R. Diseases of Finland and Scandinavia. In: Rothschild H, ed. Biocultural aspects of disease. New York: Academic Press, 1981:359-415.

34 Arts WF, de Groot CJ. Congenital nemaline myopathy: two patients with consanguineous parents, one with a progressive course. F Neurol 1983;230:123-30.

35 Kuitunen P, Rapola J, Noponen AL, Donner M. Nemaline myopathy. Report of four cases and review of the literature. Acta Paediatr Scand 1972;61:353-61. 